\title{
Художественная самодеятельность как один из факторов актуализации традиционного фольклора
}

\begin{abstract}
Аннотация: В статье раскрываются потенциальные возможности художественной самодеятельности в процессе актуализации традиционного фольклора. Описывается деятельность коллективов художественной самодеятельности с точки зрения ориентации на фольклорную культуру и традиционный фольклор как ее значимый компонент. Рассматриваются возможности творческих мероприятий по актуализации традиционного фольклора. Показано, что актуализация традиционного фольклора в рамках деятельности коллективов художественной самодеятельности, требует особых, специфических профессионалов одновременно в области фольклорной культуры, художественной самодеятельности, современной культуры в целом. С использованием метода экземплификации показаны различные варианты обращения самодеятельности к фольклору на примерах реальных ситуаций. Сравнительно-описательный метод позволил рассмотреть ориентацию коллективов художественной самодеятельности на различные элементы фольклорной культуры. В результате проведенного анализа делается заключение о том, что коллективы художественной самодеятельности демонстрируют некоторые устойчивые типичные ситуации обращения к традиционному фольклору, такие как исполнение фольклора в аутентичном варианте и в форме художественных трансформаций; включение его в более широкие сценические постановки; создание авторских произведений в «фольклорном» стиле; широкий показ в рамках творческих мероприятий.
\end{abstract}

Ключевъе слова: Традиционный фольклор, фольклорная культура, художественная культура, художественная самодеятельность, ориентация на фольклор, коллективы художественной самодеятельности, фестивали, конкурсы, концертные выступления, народные обрядовые действа.

Review: In her article Kaminskaya touches upon potentials of amateur performances in the process of actualization of traditional folklore. The researcher describes activities of amateur talent groups from the point of view of their orientation at folklore culture and traditional folklore as an important element. The author also analyzes possibilities of amateur performances to actualize traditional folklore. The author demonstrates that as part of the amateur talent group activities, actualization of traditional folklore requires special training in the spheres of folklore culture, amateur performances and contemporary culture in general. By using the method of exemplification, the author demonstrates different variants of amateur groups' appealing to folklore based on actual examples. The comparative descriptive method has also allowed the author to examine orientation of amateur talent groups at different elements of folklore culture. As a result of the analysis, the author makes a conclusion that amateur talent groups demonstrate stable patterns of appealing to folklore traditions such as performance of folklore in its authentic variant and artistic transformation, inclusion of folklore in a wider stage play, creation of works in the 'folklore' style and a wide demonstration as part of creative activities.

Keywords: Traditional folklore, folklore culture, artistic culture, amateur performances, orientation at folklore, amateur talent groups, festivals, contests, concert performances, folklore ritual actions.

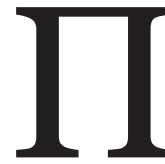

роблемы, в той или иной степени касающиеся вопросов традициональных аспектов жизни общества, достаточно часто становятся остроактуальными в периоды различных преобразований, как его политической, так и культурной сфер. Связано это, в том числе, с необходимостью в идентификации себя с социумом, потребности в самобытности, ярко проявляющихся в такие социокультурные периоды. По справедливому замечанию А. В. Головнёва «устная традиция до сих пор 
обладает существенным потенциалом этничности» [1, с. 7] (следует, на наш взгляд, уточнить, что под устной традицией в процитированной статье указанный автор подразумевает именно фольклор). Среди всего обширного круга таких проблем научные исследования в той или иной степени затрагивают проблемы бытия фольклора в современности, его сохранения, использования, возрождения, актуализации и пр. подобных действий. Так, Н. А. Хренов указывает на то, что «Фольклор находит для себя самые разные формы выражения, окрашивает восприятие современным человеком все сферы, события, личности <...> [2, с. 97]. И далее: «Оказывается, что воздействие фольклора на жизнь, общество, власть, государство, массовую коммуникацию, искусство огромно» [2, с. 98]. Среди всего спектра вопросов, освещающих судьбу фольклора в современности, важным представляется рассмотрение специальных механизмов, форм, факторов его актуализации и анализа с данной позиции различных потенциальных возможностей той или иной сферы культуры.

Одной из таких сфер выступает художественная самодеятельность, которая на определенном историческом этапе развития представляла собой одно из крупнейших по масштабам и мощных по силе воздействия социально-организованных массовых движений, основное значение которого состояло в «непосредственном приобщении широких слоев населения к занятиям искусством, овладению навыками художественного творчества, во внедрении творчества в повседневный быт» [3, с. 5]. Художественная самодеятельность в процессе своего социокультурного развития была ориентирована на воспроизводство, подражание, развитие образцов и фольклора (как и всей фольклорной культуры в целом), и некоторых видов любительского творчества, и профессиональной художественной культуры, и массовой культуры, и, отчасти - элитарной культуры.

При этом указанная ориентация могла носить и одновременный и разновременный характер. Например, в XIX веке, как отмечают исследователи, только зарождающаяся в любительских формах народного художественного творчества художественная самодеятельность была ориентирована на воспроизводство именно фольклорных образцов. Еще около пятидесяти лет назад Б. Н. Путилов отмечал, что одной из простейших форм вклю- чения традиционного фольклора в художественную самодеятельность являлся перенос выступлений фольклорных исполнителей на сцену, а на сегодняшний момент говорить об этом уже почти не приходится, к сожалению, из-за потери большей части живых носителей фольклорной традиции. И эта утрата невосполнима. Если обрядовое творчество, сами тексты традиционного фольклора, традиции декоративно-прикладного и изобразительного народного искусства можно реконструировать по фиксированным источникам (аудио-, видеозаписям, письменным материалам, материальным носителям), то саму фольклорную традицию без прямой органичной непосредственной передачи от носителей к следующему поколению восстановить крайне сложно.

C течением времени, ориентация художественной самодеятельности на профессиональную художественную культуру становится все заметнее. В XX веке художественная самодеятельность демонстрирует видо-жанровую палитру, почти аналогичную профессиональной художественной культуре; peпертуар, в большей степени совпадающий с репертуаром профессиональных коллективов (хотя и на другом качественном уровне исполнения); целенаправленную «профессионализацию» творчества. Это подтверждает «уклон» художественной самодеятельности в сторону профессиональной художественной культуры, хотя и при сохранении ориентации на фольклорные образцы творчества.

Казалось бы, художественная самодеятельность в силу большей направленности на профессиональную художественную культуру представляет собой некоторую оппозицию по отношению к традиционному фольклору. Но с позиций культурологического подхода - это принципиально иная социокультурная ситуация. Здесь в качестве акторов выступают обычные люди без специального профессионального образования в сфере искусства, культуры или традиционного фольклора. Тем самым их можно рассматривать как своеобразных «агентов влияния», включенных в среду обитания традиционного фольклора с одной стороны, в среду «населения», которое мало знакомо с традиционным фольклором, с другой. Именно участники коллективов художественной самодеятельности в данном случае будут выступать как живые носители фольклорной традиции без профессионального опосредования, как это происходит в 
профессиональной художественной культуре. В рамках межличностных микро-коммуникаций (в семье, с друзьями, с участниками иных социальных общностей) они являются распространителями данной традиции, прививают интерес к ней, способствуют ее дальнейшему развитию. Другое дело, что такие акты происходят ситуативно, спонтанно, не имеют целенаправленного воздействия, хотя содержат в себе огромный потенциал. Можно считать, что часть зрительской аудитории уже охвачена актуализацией традиционного фольклора, хотя сама она может не вполне осознавать это. При целенаправленном же воздействии такая аудитория будет представлена еще шире.

Именно своеобразное уникальное (медиальное) положение художественной самодеятельности по отношению и к профессиональной художественной культуре, и к фольклорной культуре обусловило широкий спектр ее форм, видов, жанров, а также наше пристальное внимание к ней как одному из существенных факторов актуализации традиционного фольклора. Обусловлено это несколькими обстоятельствами. Во-первых, художественная самодеятельность в существенной степени институционализирована, т.е. представляет собой специально организованные формы художественной культуры. Во-вторых, и сами эти формы, и их содержательный компонент, и ориентированность на различные художественные образцы могут включаться в ситуации «мягкого» регулирования со стороны акторов культурной политики различного масштаба. В третьих, возможность целенаправленного воздействия на различные, и что достаточно показательно - значительные по охвату, группы населения, включающие участников художественной самодеятельности и ее зрительскую (слушательскую) аудиторию, для развития интереса к фольклорной культуре, потребностей в «занятиях» фольклором. Такие «занятия» предполагают его изучение, освоение, воспроизведение, реконструкцию, исполнение и пр. Именно в художественной самодеятельности, еще раз подчеркнем, формирование и развитие интереса к традиционному фольклору, как значимой части фольклорной культуры, может приобрести достаточно широкий масштаб в силу массовой вовлеченности в эту сферу и ее участников, и аудитории, на которую она рассчитана.

Несмотря на то, что в последние двадцать - двадцать пять лет отмечаются негативные тенденции в развитии художественной самодеятельности, такие как сокращение численности ее участников, уменьшение количества коллективов, ухудшение материально-технической базы и пр., все же это явление получает более широкий резонанс, относительно «ближе» по культурной дистанции расположено по отношению к массам всей аудитории искусства. Таким образом, следует рассчитывать на то, что сам масштаб актуализации традиционного фольклора будет более значителен и ощутим.

По мнению специалистов, сама ориентация художественной самодеятельности на фольклор не одновекторна, а представляет собой несколько линий, среди которых стоит отметить направленность на народное «академическое» направление (т.е. на деятельность профессиональных народных хоров, филармонических оркестров народных инструментов и пр., как правило, демонстрирующих стилизацию под фольклор, его профессиональную трансформацию), на собственно фольклор (некоторые исследователи подразделяют такие коллективы на аутентичные, этнические, фольклорные [4, с. 7]), на синтез фольклора и массовой культуры.

Нам же представляется, что в силу специфичности художественной самодеятельности, занимающей в определенном смысле промежуточное положение между профессиональной художественной культурой и элементарными уровнями художественной активности [5, с. 164-177], одновременно диффузно взаимодействуя с ними, вариаций звучания в этой сфере фольклорных тем, образов, стилистик значительно больше.

Рассмотрим это на конкретных материалах, экземплифицируя различные варианты обращения самодеятельности к фольклору на примерах реальных ситуаций.

Одной из таких ситуаций является воспроизведение (в результате воссоздания, реконструкции, разучивания) обрядовых действ на сцене коллективами художественной самодеятельности. Такие постановки - не редкость в их деятельности. Это связано с яркостью, красочностью, зрительностью самих обрядов, возможностью демонстрации в рамках одного представления нескольких видов и жанров творчества, большой эмоциональной силой воздействия. Не случайно, даже в народных гуляниях, так широко сейчас используемых в рамках дней городов, прощания с зимой и другими официальными и полуофициальными 
мероприятиями активно задействуют именно обрядово-праздничную культуру народа. Но постановки эти могут носить исключительно развлекательный характер и быть объедены с традицией лишь наименованием или стилизацией под народные костюмы. Мы же хотим рассказать о бережном обращении к фольклорным традициям и их грамотном использовании, которые представлены, например, ежегодным фестивалем «Обрядовая культура моего села» (Орловская область). Его авторами выступили сотрудники Орловского областного центра народного творчества и станции детско-юношеского туризма и экскурсий. В рамках подготовки к этому фестивалю коллективы художественной самодеятельности готовят сценические постановки обрядов (или их фрагментов) своей локальной традиции. При этом обязательным условием является наличие «историко-теоретической справки» о бытовании обряда, его разновидностях и пр. Тем самым обращение к фольклору участниками художественной самодеятельности происходит на эмпирическом уровне (поисковая работа, сбор информации, ее запись), теоретическом (дополнение информации из научных и популярных источников), практическо-деятельностном (воплощение на сцене). При сценической постановке возможны различные варианты обращения к фольклору: и использование собственно фольклорного материала (как в текстовом, в музыкальном, так и в драматургическом компоненте), и его «осовременивание» (обработки, аранжировки народных песен, видоизменение языкового компонента), стилизация.

Такое воссоздание и воплощение на сцене в том или ином виде образцов традиционного фольклора практически невозможно без активной исследовательской и собирательской деятельности. Как правило, эту деятельность в отношении традиционного фольклора берут на себя сотрудники центров народного творчества и других подобных организаций, преподаватели и студенты ссузов и вузов (в которых проводятся фольклорные, этнографические, фольклорно-этнографические экспедиции), предоставляя руководителям и участникам художественной самодеятельности уже готовые материалы. В этом отношении описанный фестиваль - хороший образец активного включения самих участников художественной самодеятельности в этот процесс. На наш взгляд, это должно стать примером для организаторов подобных мероприятий, способствуя сохранению, возрождению и актуализации традиций, которые в результате отсутствия такой целенаправленной и систематической работы могут быть безвозвратно утеряны; активизируя познавательную активность людей; развивая чувство патриотизма по отношению к «малой Родине».

Поскольку, действительно, одной из самых ярких демонстраций творчества коллективов художественной самодеятельности, являются их концертно-творческие выступления, то они в значительной мере являются показателями их «направленности» либо на фольклор, либо на профессиональную художественную культуру. Можно назвать огромное количество концертов, конкурсов, фестивалей, проводимых и самими коллективами художественной самодеятельности, и для них, целью которых ставится сохранение, возрождение фольклорных традиций, показ спектра фольклорных жанров и т.п. Только их перечисление займет достаточно много места, но, все равно, не охватит их полный перечень. Такие фестивали и конкурсы постоянно организуются, видоизменяются, расширяются, отдельные направления в них вырастают до собственных фестивалей и конкурсов и т.д. Приведем лишь некоторые примеры: фестивали «Зеленые святки», «Живая вода», «Заваленка», «Надежда», «Играй, душа», «Голоса народных инструментов», «Волжские зори», «Культурное наследие народов Поволжья», «Музыкальная осень Ставрополья», Бажовский фестиваль, фестивали народного творчества им. А. П. Мистюкова и «Песня - душа России», фестивали-конкурсы «Золотое кольцо», «Поет село родное», народной песни, музыки и танца «Малахитовый узор», исполнителей народной песни «Певчий край», оркестров и ансамблей народных инструментов памяти С. Я. Садакова, конкурс-фестиваль молодых исполнителей славянской народной песни «Оптинская весна», конкурсы исполнителей на русских народных инструментах им. М. А. Матренина, исполнителей народной песни имени Надежды Плевицкой, «Европа-Азия» и т.д. (наименование этих мероприятий взято из журналов «Народное творчество», «Клуб и художественная самодеятельность» и др.).

В различных регионах страны со схожими названиями проводятся разные по сути творческие выступления: где то конкурс, где-то фестиваль, где-то конкурс-фестиваль. К сожалению, нет никакого даже примерного реестра 
всех существующих наименований конкурсов, их четкого определения, иногда - ясного видо-жанрового наполнения. Как правило, на подобного рода мероприятиях выдают дипломы лауреатов и дипломантов, определяются места и т.д. Это само по себе нивелирует такие понятия, как фестиваль, конкурс, концертное выступление, сводя все к демонстрации творческих достижений коллектива или отдельного исполнителя. Зачастую, в их рамках номинации, в той или иной степени связанные с фольклором, представлены в более широком спектре видо-жанровой палитры концерта, фестиваля, конкурса.

Яркой демонстрацией исполнительских и творческих возможностей и результатов деятельности коллектива художественной самодеятельности являются его концертные выступления. В них фольклор может быть представлен среди других направлений художественной культуры: исполнение авторских (самодеятельных и профессиональных авторов) песен, показ авторских спектаклей, исполнение переложений профессиональных произведений и пр. Вместе с тем концертное выступление может показать особенности воплощения фольклорных традиций в рамках одного коллектива: это и исполнение подлинных фольклорных произведений, и обработки (аранжировки), и создание попурри на народные мелодии, и слияние жанров (например, музыкальный спектакль по фольклорным мотивам: «Гуси-лебеди», «Ай, да, Колобок!», «Как бы не так» и др.), и современная «подача» фольклорного материала. Таким образом мы видим спектр возможностей претворения традиционного фольклора в рамках деятельности того или иного коллектива художественной самодеятельности.

Даже в таком беглом и, отчасти, поверхностном перечислении мы можем увидеть различные грани «показа» традиционного фольклора в рамках указанных творческих мероприятий художественной самодеятельности. Конечно же, мы понимаем, что такие фестивали, конкурсы, концерты не всегда ставят целью сохранение, возрождение и даже демонстрацию традиционного фольклора. Иногда они преследуют более узконаправленные задачи: выявление наиболее выдающихся исполнителей, отбор значимых произведений и пр. Но мы будем рассматривать их именно под таким исследовательским углом: как в рамках этих мероприятий «использован» традиционный фольклор. В результате проведенного анализа мы пришли к следующим выводам. Международные фестивали демонстрируют максимальный спектр видо-жанровой и этнической палитры традиционного фольклора: и вокальные, и инструментальные (сольные), и ансамблевые (вокальные ансамбли, ансамбли народных инструментов, группы, в т. ч. театральные), и групповые формы (хоры, оркестры, театры) выступлений различных народов и даже стран. Такое разнообразие позволяет участникам коллективов, которые зачастую бывают и зрителями на данного рода мероприятиях, и, собственно, зрителям, и жюри увидеть широкий спектр традиций, способы их воплощения (исполнение подлинных образцов, сценический вариант, придание современного колорита и пр.), многообразие исполнителей и участников художественной самодеятельности. В этом мы видим и обмен опытом, который возникает непроизвольно (хотя может быть и специально организован путем проведения мастер-классов, круглых столов и пр.), как ориентация на понравившиеся выступления, обмен репертуаром, совместные исполнения не в рамках концертной (конкурсной) программы и т.д. Это способствует распространению различных форм фольклорной культуры, в том числе, и традиционного фольклора, являющегося ее значимой частью. Всероссийские конкурсы ориентированы на показ не менее широкого спектра обращений художественной самодеятельности к традиционному фольклору, ведь в нашей стране проживает большое количество народов, готовых и желающих продемонстрировать свое национальное (этническое) искусство. А вот региональные и областные творческие мероприятия демонстрируют нам спектр видо-жанровой палитры фольклора в пределах, как правило, одной этно-локальной традиции. Хотя на тех территориях, где произошло слияние культур, фольклорные коллективы могут демонстрировать различные традиции в рамках одной этно-национальной группы. В качестве доказательства этому стоит привести Челябинскую область, среди русского населения которой можно встретить самодеятельные коллективы, ориентированные на крестьянскую фольклорную традицию (например, вокальный ансамбль «Русская душа», хор «Родные напевы», фольклорный ансамбль «Славица», ансамбль «Изумруд» и мн. др.) и на казачью традицию (например, ансамбль 
народной песни «Тугайкуль», ансамбль казачьей песни «Субботея», мужской вокальный ансамбль «Ясный сокол», ансамбль «Певуньи России» и мн. др.). Это не говоря уже о коллективах художественной самодеятельности других народов. И все же на региональных, областных, городских творческих мероприятиях, по сравнению с международными, в рамках нашего исследовательского интереса, доминантным становится показ различных трансформаций традиционного фольклора в рамках одной этно-локальной традиции.

Творческие мероприятия могут, условно говоря, быть «профильными», т.е. сосредоточенными только на одном из видов традиционного фольклора: чаще, это исполнение народных песен, игра на народных инструментах (уже указанные конкурс-фестиваль молодых исполнителей славянской народной песни «Оптинская весна», фестиваль-конкурс исполнителей народной песни «Певчий край», фестиваль-конкурс оркестров и ансамблей народных инструментов памяти С. Я. Садакова, конкурс исполнителей на русских народных инструментах им. М. А. Матренина; конкурс исполнителей народной песни им. Л. А. Руслановой, конкурс исполнителей бурятских народных песен, конкурс исполнителей народной песни им. Н. Плевицкой, конкурс исполнителей народной песни «Надежда» и мн. др.). В рамках таких творческих мероприятий коллективы и участники художественной самодеятельности демонстрируют собственное исполнительское мастерство воплощения фольклора в рамках небольшого концертного выступления. В данном случае вопрос акцентируется на профессиональных навыках участника, как бы отодвигая на второй план собственно традиционный фольклор. И все же такие конкурсы показывают нам спектр обращений, использований и претворений традиционного фольклора в рамках одной исполнительской формы.

Несмотря на красочность, яркость, зрелищность такого рода мероприятий, они не лишены собственных специфических проблем. «Бум-мода» на фольклор, существовавшая около двадцати лет назад в связи с распадом государства и поиском национальной и этнической идентичности, породила большое количество коллективов квази-фольклорного толка. Но зачастую их репертуарная политика показывает, что они используют не только и не столько фольклор (пусть даже в трансфор- мированном варианте), сколько авторские произведения, стилизованные под фольклор (сочинения «в духе»). Это, конечно же, не умаляет достоинств коллективов, но и не способствует делу актуализации традиционного фольклора. В жюри описываемых конкурсов, фестивалей могут даже не присутствовать специалисты «фольклорного направления», хотя формально номинация может быть заявлена. Многие участники таких творческих мероприятий, их зрители отмечают, что за огромным количеством коллективов (что, зачастую, объясняется экономической составляющей) теряется специфика и самобытность каждого. В этом отношении особое место занимают фестивали фольклора, фестивали этнической культуры, например, «Иске Казан тугэрэк уены», «Ауаз», ставящие целью не просто демонстрацию традиций, но и «пропаганду актуальности» [6] национальных культур. Целесообразными видятся подобные практики как примеры такого рода и для других творческих показов. Следует отметить, что проведение таких творческих мероприятий характерно не только для нашей страны и стран ближнего Зарубежья (Украина, Белоруссия, Казахстан и пр.), но и для дальнего Зарубежья. Например, в Китае проводится международный фестиваль национальных (народных) песен, в рамках которого их исполнители встречаются со студентами вузов, демонстрируют им свое искусство, тем самым обеспечивая знакомство, поддержку интереса к ним, дальнейшее развитие традиции. Еще одним примером можно считать фестивали, проводимые под патронажем Смитсоновского института в Вашингтоне (США) при сотрудничестве с различными национальными культурными фондами на определенные заданные темы, связанные с фольклором какой-либо страны или с фольклорными традициями этнических групп Америки. Важнейшим критерием при отборе коллективов является их непрофессиональность (!), представление живых исконных традиций. В рамках фестиваля проводятся обсуждения важнейших вопросов, связанных с этническими культурами, выставки, демонстрация литературы и пр. Указанные фестивали могут стать хорошими примерами актуализации традиционного фольклора для организаторов творческих мероприятий и в нашей стране. Ведь большинство из них жалуются на то, что фольклорные традиции забываются, исчезают со временем, не остается их живых носителей. В то же время, почти отсутствуют 
механизмы целенаправленного сохранения, поддержания, введения в современные практики традиционного фольклора в рамках деятельности коллективов художественной самодеятельности. Хотя проблема такая существует и поиски ее решения продолжаются. Так, например, в рамках некоторых фестивалей и конкурсов проводятся круглые столы с обсуждением вопросов, связанных с указанной тематикой. Опять-таки, к сожалению, отметим, что зачастую такие круглые столы сводятся к обсуждению исполнительских достоинств и недостатков коллективов, разбором наиболее удачных и неудачных моментов выступлений, реже - встрече с носителями фольклорной традиции, совсем нечасто - выявлению наиболее проблемных зон в отношении традиции и поиску решений для их устранения. А ведь еще в конце 80-х годов XX века известный фольклорист А. Кабанов ставил подобные вопросы и даже предлагал пути их решения. При этом он отдельно обозначал варианты для городской и сельской художественной самодеятельности и даже выдвигал идею создания специальных учреждений нового типа [7, с. 41-42].

В целом, идеи, описанные А. С. Кабановым, актуальны и на сегодняшний день. Разница состоит лишь в том, что сейчас, спустя более двадцати пяти лет после его выступления, и в сельской местности иногда отсутствуют фольклорные коллективы, группы, индивидуальные носители фольклорной традиции, от которых можно было бы ее записать, кого можно было бы привлечь в качестве педагогов-наставников для передачи новым поколениям. Но они еще есть. В связи с этим, указанные проблемы приобретают большую остроту, а задачи требуют незамедлительного решения.

Основным результативным суждением, которое можно сформулировать в контексте взглядов А. С. Кабанова, является, на наш взгляд, следующее: в его позиции изложены, скорее, программные установки в деле сохранения и актуализации традиционных фольклорных форм. В то же время, совершенно ясно, что в современных условиях такая культурная миссия практически невыполнима без участия специалистов особого профиля, специализирующихся именно в проблематике фольклорной культуры и способных эффективно координировать деятельность представителей различных сфер (в том числе и художественной самодеятельности) в достижении ощутимых результатов.
В этом случае мы можем говорить об особом статусе руководителя коллектива художественной самодеятельности, который для решения поставленных задач должен быть своеобразным специалистом, глубоко постигшим основные закономерности развития традиционного фольклора, его родо-видо-жанровую палитру, тексты, стилистику, с одной стороны; закономерности профессиональной художественной культуры (возможность сценического воплощения, особенности трансформации образцов (аранжировки, обработки, вариации, стилизацию и пр.), репертуарную политику и т.п.), с другой; специфику образовательного процесса (формирование и развитие определенных умений и навыков у участников художественной самодеятельности, достижение ими определенного исполнительского уровня), с третьей.

Но этим, на наш взгляд, дело не ограничивается. Помимо специфичных в контексте нашей проблематики навыков руководителей самодеятельных фольклорных коллективов, несомненно, способных внести весомую лепту в актуализацию традиционного фольклора, есть аспекты этого процесса, работать с которыми предназначены профессиональные фигуры несколько иного плана. Дело в том, что специфичность художественной самодеятельности, помимо прочего, включает определенный уровень самодостаточности, предполагающий, по сравнению с профессиональным искусством, менее выраженный акцент на регулярную трансляцию результатов своего творчества на широкую аудиторию. Для участников художественной самодеятельности представляет интерес сам процесс занятий искусством, не исключающий вынесение его результата на суд публики, но лишь в качестве одного из компонентов самодеятельного творчества, тогда как в профессиональном искусстве это выступает основным результирующим моментом.

Это некоторое отступление потребовалось для того, чтобы обозначить определенные черты «профессиограммы» специалиста в сфере фольклорной культуры, способного видеть ее составляющие и в соотношении друг с другом, и в контекстах актуальных социокультурных ситуаций. Именно специалист такого профиля может грамотно использовать потенциал столь своеобразного явления, как художественная самодеятельность, включая представителей этой сферы в такие контексты, в которых возможности самодеятельных 
коллективов, групп и объединений дадут наибольший эффект в деле распространения, сохранения и актуализации традиционных фольклорных форм. Пока же ситуации такого рода практик возникают спорадически, несистемно, в локальных ситуациях и дают ощутимо меньший эффект, чем того заслуживает само явление традиционного фольклора.

Удачное сочетание традиционного фольклора с современным его звучанием демонстрирует арт-фолк оркестр (группа) «Морденс», в творчестве которой сочетаются разнообразные музыкальные стили: академический и народный вокал, рок. При этом за основу берутся подлинные мордовские мелодии. Благодаря «осовремениванию» звучания, выступления коллектива пользуются огромной популярностью у слушателей. Группа была организована как коллектив художественной самодеятельности, но с 2010 г. обрела статус профессионального коллектива. Это еще раз доказывает нашу мысль о том, что грань между различными структурными компонентами художественной культуры (профессиональной и непрофессиональной) очень тонка и подвижна. В репертуаре коллектива воссоздано в сценической постановке обрядовое действие мордовского народа «Әрямонь Парь» («Кладезь жизни»), в котором органично сочетаются несколько обрядов и ритуалов: свадебный обряд, обряд проводов на службу, очистительные обряды. По словам руководителя группы А. С. Алешкина, в сценическом воплощении этих обрядов очень много импровизационного, каждый раз на сцене возникают различные варианты действия с сохранением основного стержня (так, как это и свойственно традиционному фольклору). При этом участники коллектива - профессиональные артисты Мордовского государственного драматического театра, т.е. люди, обладающие профессиональными знаниями и умениями актерского воплощения образов. Такое удачное грамотное сочетание профессионализма и фольклорности может послужить примером яркого воплощения и актуализации традиционного фольклора.

В качестве еще одного примера сохранения и актуализации традиционных фольклорных форм следует привести сочетание исполнительских фольклорных традиций с традициями декоративно-прикладного искусства. В рамках выставок, фестивалей ДПТ нередко приглашаются творческие исполнительские коллективы. Так, например, фести- валь «Игрушка-говорушка» включает не просто демонстрацию образцов традиционной игрушки, обмен опытом между их мастерами, но и выступления фольклорных коллективов, народные гуляния, тематические театрализованные постановки, мастер-классы и творческие лаборатории по исполнительскому искусству. Это способствует представлению более широкого спектра традиций, видению их взаимосвязи, делает мероприятия красочными, зрелищными, что способствует привлечению достаточного количества и участников, и публики. На наш взгляд, это также способствует формированию и развитию интереса к традициям, к фольклорной культуре в целом, к традиционному фольклору, как ее существенному компоненту. Слияние различных мотивов и форм традиционного фольклора, как правило, имеют достаточно широкий общественный резонанс, тем самым еще большее количество людей знакомиться с фольклорными традициями, может проявить заинтересованность, включиться в самодеятельное движение. Это, в свою очередь, будет служить делу актуализации традиционного фольклора. В рамках подобного рода мероприятий «рождаются» школы, клубы, объединения традиционной культуры, ставящие своей задачей, в том числе, передачу фольклорных традиций, объединяющие в своей работе собирательскую, творческую, исполнительскую деятельность. Такие клубы и школы, особенно создающиеся и функционирующие в рамках системы дополнительного образования детей, представляют собой некий переходный элемент от собственно художественной самодеятельности к образовательной среде. В их деятельности заложен огромный воспитательный потенциал развития патриотического чувства, формирования и развития интереса и любви к собственным традициям, к своему фольклору, и, уже через это, к своей стране, обладающей таким огромным пластом культуры, как традиционный фольклор, сумевшей его сохранить, воссоздать, реконструировать, актуализировать и использовать в современных культурных практиках.

На наш взгляд, в приведенных примерах заложен один их существенных для нашей темы моментов: целенаправленное использование своеобразных ситуаций «встреч», пересечений и взаимодействий различных явлений фольклорных традиций, как между собой, так и с другими современными явлениями культуры на одних площадках, в рамках которых сама фольклорная 
культура предстает достаточно полно, происходит взаимообогащение всех соучаствующих в таком социокультурном «проекте».

Возрождение фольклорных традиций происходит и в рамках деятельности инструментальных ансамблей художественной самодеятельности. При этом имеются в виду не все ансамбли, а использующие так называемые «инструменты фольклорной традиции»: рожки, кугиклы, жалейки и пр. Как правило, руководитель такого ансамбля - мастер по их изготовлению и, одновременно, исполнитель на них. Именно в силу необычной для современного слушателя звуковой окраски такие инструменты становятся своеобразной «изюминкой» концертной программы и получают более широкое распространение. И опять-таки, как и в случае со сценическими воплощениями обрядов, возможно исполнение собственно народных мелодий - наигрышей (хотя материал этот практически утерян в связи с гонениями на скоморохов), исполнение известных народных песен, исполнение авторских произведений, написанных как специально для таких инструментов, так и переложения для них.

Исходя из приведенных примеров, мы можем говорить о том, что в целом, коллективы художественной самодеятельности демонстрируют следующие типичные ситуации обращения к традиционному фольклору:

- исполнение фольклорных образцов в подлинном виде, без «трансформаций»;

- исполнение во всем спектре вариантов, который уже демонстрировала профессиональная художественная культура: обработки, аранжировки, инструментовки традиционного фольклора, вплоть до стилизации;

- включение в сценические композиции: опять-таки и без трансформации, и с переработкой традиций, вплоть до стилизации;

- сценические постановки фольклорных обрядов, которые могут включать (не всегда) исследовательскую деятельность руководителей по поиску обрядов, их записи исполнению без «корректив», либо с ними;

- возрождение традиций народно-инструментального исполнительства с использова- нием образцов подлинного фольклорного материала, его обработок, переложений, инструментовок, стилизаций, создания авторских произведений «в духе»

- авторские произведения в народном стиле с использованием фольклорной стилистики (тематика, мелодизм, особенности метроритмической структуры, ладовые стилизации и пр.);

- творческие мероприятия, демонстрирующие полный спектр от применения традиционного фольклора до стилизации под него.

Как отмечает А. С. Каргин: «Сегодня можно говорить и о взаимном процессе заимствования технико-исполнительских приемов, широко «кочующих» из фольклора в самодеятельность, и обратно. <...> Художественная самодеятельность перерабатывает традиции фольклора, его образцы в духе своих эстетических норм и критериев, и наоборот, фольклор воспринимает лишь то, что близко ему. Результатом постоянного и тотального взаимодействия фольклора и художественной самодеятельности стало, в частности, появление промежуточных форм фольклора, отличающихся в известном смысле неустойчивостью и тяготением одновременно к обеим формам творчества» [8, с. 263-264].

В силу указанного, именно художественная самодеятельность выступает той самой социокультурной средой, на которую должны быть направлены усилия по актуализации традиционного фольклора. Конечно же, в силу большой свободы творчества и волеизъявления (занятия художественной самодеятельностью - дело добровольное, желанное, с особой мотивацией и увлеченностью) технологии целенаправленного воздействия должны быть проработаны с особой тщательностью и щепетильностью, через конструирование особых форм экспликации в творчество, конструирование ситуаций грамотного использования фольклора и пр.

Следовательно, необходимо констатировать факт наличия потенциальных возможностей художественной самодеятельности в процессе актуализации традиционного фольклора и важности ее рассмотрения как одного из существенных факторов этого процесса.

\section{Библиография:}

1. Головнёв А. В. Уральские этнодиалоги // Уральский исторический вестник. 2013. № 2 (39). С. 4-16.

2. Хренов Н. А. Судьба традиционной культуры в постиндустриальной цивилизации // Модернизация культуры: идеи и парадигмы культурных изменений: матер. Междунар. науч. - практич. конф. под ред. С. В. Соловьевой, В. И. Ионесова, Л. М. Артамоновой. 2014. С. 93-116. 
3. Путилов Б. Н. Фольклор и художественная самодеятельность // Фольклор и художественная самодеятельность / отв. ред. Н. В. Новиков. Ленинград: Наука, 1968. С. 5-19.

4. Организация работы самодеятельных фольклорных коллективов: метод. рекомендации для работников социокультурной сферы / сост. Т. С. Чекмарева, А. Ф. Мингадеева. Казань, 2013. 38 с.

5. Соковиков С. С. Популярная культура: аспекты исследования: моногр. / Челяб. гос. акад. культуры и искусств. Челябинск, 2014. 206 с.

6. Х Хурамшина Р. Фестиваль «Ауаз» способствует сохранению башкирской этнической культуры URL: http:// rentrb.ru/news/328. (дата обращения: 26.08.2015).

7. Кабанов А. С. Музыкальное фольклорное направление в современном народном творчестве // Художественная самодеятельность. Фольклор: проблемы сохранения, изучения и пропаганды: тез. Всесоюз. науч. - практ. конф. В 2-х ч. Москва, 1988. С. 40-42.

8. Каргин А. С. Народная художественная культура: курс лекций для студентов высш. и сред. учеб. заведений культуры и искусств: учеб. Москва: Гос. республик. центр рус. фольклора, 1997. 288 с.

9. Хренов Н. А. Модернизационные процессы на рубеже XX-XXI веков и судьба традиционных ценностей // Культура и искусство. 2013. № 5. С. 544-555. DOI: 10.7256/2222-1956.2013.5.9570.

10. Балдина О. Д. Предметно-материальный мир народной культуры в сфере современной коммуникации: «контактные зоны» // Культура и искусство. 2013. № 1. С. 61-73. DOI: 10.7256/2222-1956.2013.01.7.

11. Обморокова А.M. Отражение процессов региональной идентификации и самоидентификации в красноярском культурном пространстве (на материале анализа концепта «Родина») // Социодинамика. - 2015. 3. - C. 69 - 93. DOI: 10.7256/2409-7144.2015.3.14677. URL: http://www.e-notabene.ru/pr/article_14677.html

\section{References (transliterated):}

1. Golovnev A. V. Ural’skie etnodialogi // Ural'skii istoricheskii vestnik. 2013. № 2 (39). S. 4-16.

2. Khrenov N. A. Sud'ba traditsionnoi kul'tury v postindustrial'noi tsivilizatsii // Modernizatsiya kul'tury: idei i paradigmy kul'turnykh izmenenii: mater. Mezhdunar. nauch. - praktich. konf. pod red. S. V. Solov'evoi, V. I. Ionesova, L. M. Artamonovoi. 2014. S. 93-116.

3. Putilov B. N. Fol'klor i khudozhestvennaya samodeyatel'nost'// Fol'klor i khudozhestvennaya samodeyatel'nost' / otv. red. N. V. Novikov. Leningrad: Nauka, 1968. S. 5-19.

4. Sokovikov S. S. Populyarnaya kul'tura: aspekty issledovaniya: monogr. / Chelyab. gos. akad. kul'tury i iskusstv. Chelyabinsk, 2014. 206 s.

5. Khuramshina R. Festival' «Auaz» sposobstvuet sokhraneniyu bashkirskoi etnicheskoi kul'tury URL: http:// rentrb.ru/news/328. (data obrashcheniya: 26.08.2015).

6. Kabanov A. S. Muzykal'noe fol'klornoe napravlenie v sovremennom narodnom tvorchestve // Khudozhestvennaya samodeyatel'nost'. Fol'klor: problemy sokhraneniya, izucheniya i propagandy: tez. Vsesoyuz. nauch. prakt. konf. V 2-kh ch. Moskva, 1988. S. 40-42.

7. Kargin A. S. Narodnaya khudozhestvennaya kul'tura: kurs lektsii dlya studentov vyssh. i sred. ucheb. zavedenii kul'tury i iskusstv: ucheb. Moskva: Gos. respublik. tsentr rus. fol'klora, 1997. 288 s.

8. Khrenov N. A. Modernizatsionnye protsessy na rubezhe XX-XXI vekov i sud'ba traditsionnykh tsennostei // Kul'tura i iskusstvo. 2013. № 5. S. 544-555. DOI: 10.7256/2222-1956.2013.5.9570.

9. Baldina O. D. Predmetno-material'nyi mir narodnoi kul’tury v sfere sovremennoi kommunikatsii: «kontaktnye zony» // Kul'tura i iskusstvo. 2013. № 1. S. 61-73. DOI: 10.7256/2222-1956.2013.01.7.

10. Obmorokova A.M. Otrazhenie protsessov regional'noi identifikatsii i samoidentifikatsii v krasnoyarskom kul'turnom prostranstve (na materiale analiza kontsepta "Rodina") // Sotsiodinamika. - 2015. - 3. - C. 69 - 93. DOI: 10.7256/2409-7144.2015.3.14677. URL: http://www.e-notabene.ru/pr/article_14677.html 